\title{
From JRSM Short Reports
}

JRSM Short Reports is a new, online-only, peerreviewed, open-access companion journal to JRSM. JRSM Short Reports was launched in June 2010 and will develop into a leading international online resource of clinical papers and case reports on all aspects of improving patient care. As with other open access journals, authors are required to pay a small fee for published articles to cover the production costs and ensure that their article is freely available to readers.

You can find JRSM Short Reports on the Internet at http://shortreports.rsmjournals.com. To submit a clinical paper or case report to JRSM Short Reports visit http://mc.manuscriptcentral.com/sh orts. For submission inquiries contact Dr Kamran Abbasi, editor of JRSM and JRSM Short Reports, by email at kamran.abbasi@rsm.ac.uk.

Articles published in JRSM Short Reports will also be mentioned in the print edition of JRSM. Here are the articles published in JRSM Short Reports in June and July 2010:

\section{Research}

- Shaban F, Stewart K, Kalima P. Does mixing acute medical admissions with burn patients increase infective complications from paediatric thermal injuries? J $R$ Soc Med Sh Rep 2010;1:1

- Jacques TS, Sebire NJ. The impact of article titles on citation hits: an analysis of general and specialist medical journals. J $R$ Soc Med Sh Rep 2010;1:2

- Doyle C, Reed J, Woodcock T, Bell D. Understanding what matters to patients identifying key patients' perceptions of quality. J R Soc Med Sh Rep 2010;1:3

- Patel S, Colaco HB, Hossain FS. Factors influencing foundation programme choice among medical students. J $R$ Soc Med Sh Rep 2010;1:4

- Sakçak İ, Mehmet Avşar F, Coşgun E. Comparison of the application of low concentration and $80 \%$ phenol solution in pilonidal sinus disease. $J R$ Soc Med Sh Rep 2010;1:5

- Peters TJ, Levell NJ. Re-evaluation of the diagnosis of porphyria cutanea tarda in Admiral Sir Francis Beaufort. J R Soc Med Sh Rep 2010;1:13

- Masri I, Robinson R. Glaucoma medication ignored in general medical and surgical patients. J R Soc Med Sh Rep 2010;1:16

- Chuo CB, Wright TC, Breuning E, Mendonca D. Achieving 18-week waiting times in elective hand surgery. J R Soc Med Sh Rep 2010;1:17

\section{Case reports}

- Lin M-T, Kuo P-H. Pulmonary lipiodol embolism after transcatheter arterial chemoembolization for hepatocellular carcinoma. J R Soc Med Sh Rep 2010;1:6

- Shehzad KN, Riaz A, Meyrick-Thomas J. Primary aortoduodenal fistula - a rare clinical entity. J R Soc Med Sh Rep 2010;1:7

- Freilich S, Usmani OS, Polkey MI, Hopkinson NS. Emphysema due to smoke from a herbal asthma remedy. J R Soc Med Sh Rep 2010;1:8

- Maund I, Banham-Hall E, Mallinson R. Local thrombolytic therapy for primary axillosubclavian vein thrombosis. J R Soc Med Sh Rep 2010;1:9

- Parvizi N, Shalhoub J, Davies AH. Buerger's disease: a multidisciplinary diagnostic and therapeutic challenge. J $R$ Soc Med Sh Rep 2010;1:10

- AlMahdy H, Martindale S. Polymyalgia rheumatica presenting as nocturnal fever of undetermined origin. J R Soc Med Sh Rep 2010;1:11

- Daher IN, Bathina JD, Bukhari FJ, Yusuf SW. Saddle pulmonary embolism with normal right ventricular function: a treatment enigma. J R Soc Med Sh Rep 2010;1:12

- Kearsey C, Fernando P, D'Costa D, Ferdinand $P$. The use of the ice pack test in myasthena gravis. J R Soc Med Sh Rep 2010;1:14 
- Papadia C, Coruzzi A, Montana C, DiMario F, Franze A, Forbes A. Omega-3 fatty acids in the maintenance of ulcerative colitis. J $R$ Soc Med Sh Rep 2010;1:15

- Bedi N, El-Husseiny T, Buchholz N, Masood J. 'Putting lead in your pencil': self-insertion of an unusual urethral foreign body for sexual gratification. J R Soc Med Sh Rep 2010;1:18

- Barrett G, Williams C, Thomas D. Delayed presentation of a penetrating neck injury: diagnostic and management difficulties with retained organic material. J $R$ Soc Med Sh Rep 2010;1:19

- Khan D, Corcoran J, Dungarwalla M, Bhattacharya M, Raza M. Cought and a sore throat - more than just swine flu? J R Soc Med Sh Rep 2010;1:20

- Cottle LE, Sargur R, Egner W, Shackley F, Grieg J. Susceptibility to mycobacterial infection in a young man with a hypoglossal nerve palsy: the hunt for an immunological defect. J R Soc Med Sh Rep 2010;1:21 